\title{
Faktor-Faktor yang Mempengaruhi Konsumsi Beras di Desa Babotin Maemina Kecamatan Botin Leobele Kabupaten Malaka
}

\author{
Andreas Asa ${ }^{\mathrm{a}}$ \\ ${ }^{a}$ Fakultas Pertanian, Universitas Timor, Kefamenanu, TTU - NTT, Indonesia.
}

\section{Article Info}

\section{Article history:}

Received 2 Agustus 2018

Received in revised form 23 Agustus 2018

Accepted 14 September 2018

\section{DOI:}

https://doi.org/10.32938/ag.v3i4.324

\section{Keywords:}

Beras

Desa Babotin

Konsumsi

\section{Abstrak}

Desa Babotin Maemina merupakan salah satu desa yang mengalami peralihan pola konsumsi dari pangan non beras ke pangan beras di Kabupaten Malaka. Penelitian ini bertujuan untuk mengetahui pola konsumsi beras dan faktor-faktor yang mempengaruhi konsumsi beras di Desa Babotin Maemina Kecamatan Botin Leobele Kabupaten Malaka. Penelitian dilakukan di Desa Babotin Maemina Kecamatan Botin Leobele Kabupaten Malaka yang dimulai dari bulan Juni sampai dengan September 2017 dengan menggunakan metode survei. Populasi dalam penelitian ini adalah seluruh masyarakat di Desa Babotin Maemina yang berjumlah 228 KK. Pengambilan sampel dilakukan dengan metode sensus yaitu seluruh populasi diambil sebagai sampel. Untuk mendapatkan gambaran pola konsums beras dilakukan analisis deskriptif kualitatif, sedangkan untuk mengetahui faktor-faktor yang mempengaruhi konsumsi beras digunakan analisis regresi linier berganda. Hasil penelitian menunjukkan bahwa tahun 2012 masyarakat Desa Babotin Maemina mulai beralih dari pola konsumsi pangan non beras ke beras. Rata-rata konsumsi beras dari 228 KK di Desa Babotin Maemina adalah 24,43 kg/kapita/bulan dengan rata-rata harga beras di tingkat konsumen Rp9.951,00. Harga beras dan jumlah tanggungan keluarga secara nyata berpengaruh terhadap konsumsi beras sedangkan pendapatan konsumen, tingkat pendidikan dan selera tidak berpengaruh terhadap konsumsi beras. Jika harga beras meningkat satu rupiah maka permintaan akan beras akan menurun sebesar $0,512 \mathrm{~kg}$ dan setiap penambahan satu orang sebagai tanggungan keluarga maka konsumsi beras akan meningkat $0,749 \mathrm{~kg}$.

\section{Pendahuluan}

Beras merupakan salah satu makanan pokok yang mampu menghasilkan energi terbesar dibandingkan sumber karbohidrat yang lain. Menurut data BPS Provinsi NTT, (2016) dalam 100 gram beras menghasilkan energi sebesar 129 kilokalori, dibandingkan sumber karbohidrat lain seperti jagung yang hanya menghasilkan 86 kalori dan ubi kayu 86 kalori. Hal ini menyebabkan beras merupakan konsumsi pangan pokok yang dikonsumsi oleh hampir semua penduduk di dunia.

Perubahan pola konsumsi masyarakat Kabupaten Malaka dari sumber karbohidrat yang lain ke pangan beras disebabkan oleh pengetahuan masyarakat mengenai pangan beras. Hasil penelitian Muttaqin, (2008) mengatakan bahwa, beras bersifat inelastis menunjukkan bahwa berapa pun harga beras masyarakat mengonsumsi beras sebagai makanan pokok. Data BPS Kab. Malaka, (2016) menunjukkan bahwa dari 177.892 penduduk di Kabupaten Malaka, sebesar 2,78 persen masyarakat di Desa Babotin Maemina mengonsumsi pangan beras sebagai makanan pokok. Hal ini berpengaruh besar terhadap pola konsumsi pangan beras terhadap sumber karbohidrat yang lain.

Desa Babotin Maemina merupakan salah satu desa yang mengalam peralihan pola konsumsi dari pangan non beras ke pangan beras. Hal in disebabkan pengetahuan masyarakat tentang sumber karbohidrat dari pangan beras, lebih tinggi dari sumber karbohidrat non beras menyebabkan masyaraka lebih mengonsumsi pangan beras sebagai makanan pokok. Meskipun pendapatan masyarakat rendah, mereka tetap mengonsumsi pangan beras sebagai makanan pokok dengan menjual komoditi lain untuk membeli beras Beras merupakan kebutuhan yang sangat esensial karena pangan beras lebih mudah dimasak dalam waktu yang singkat. Survei awal menunjukkan masyarakat harus melewati jarak tempuh $\pm 8 \mathrm{~km}$ untuk mendapatkan beras dari toko atau pasar.

Berdasarkan data yang diperoleh dari BPS Kab. Malaka, (2016) konsumsi pangan beras selama empat tahun terakhir yakni tahun 2012 sebanyak 0,30 persen, tahun 2013 sebanyak 4,16 persen, tahun 2014 sebanyak 25,22 persen, dan tahun 2015 sebanyak 37,71.

Jenis Beras yang di konsumsi masyarakat Desa Babotin Maemina adalah Bulog karena jenis beras ini sering di bagikan oleh pemerintah kepada masyarakat melalui program Raskin. Selain itu masyarakat juga membeli di toko dan di pasar dengan jenis yang berbeda. Untuk memahami lebih dalam tentang pola konsumsi beras masyarakat Desa Babotin Maemina maka perlu dilakukan kajian dengan topik Faktor-Faktor yang Mempengaruhi Konsums Beras di Desa Babotin Maemina Kecamatan Botin Leobele Kabupaten Malaka Penelitian ini bertujuan untuk mengetahui pola konsumsi beras dan faktor faktor yang mempengaruhi konsumsi beras di Desa Babotin Maemina Kecamatan Botin Leobele Kabupaten Malaka.

\section{Metode}

Penelitian ini dilakukan di Desa Babotin Maemina Kecamatan Botin Leobele Kabupaten Malaka yang dimulai dari bulan Juni sampai dengan September 2017. Pengumpulan data dilakukan dengan metode survei. Data yang dikumpulkan berupa data primer dan data sekunder. Data primer adalah data-data yang diperoleh melalui wawancara dengan responden berdasarkan daftar pertanyaan yang di siapkan sebelumnya, sedangkan data sekunder adalah data yang diperoleh instansi terkait. Populasi dalam penelitian ini adalah seluruh masyarakat di Desa Babotin Maemina yang berjumlah $228 \mathrm{KK}$ Pengambilan sampel dilakukan dengan metode sensus yaitu seluruh populas diambil sebagai sampel (228 KK).

Pengamatan dan konsep pengukuran yang digunakan meliputi 1) identitas responden antara lain umur (tahun), jenis kelamin (L/P), alamat, tingkat pendidikan (SD, SMP, SMA, Sarjana); 2) jumlah tanggungan keluarga (orang); 3) konsumsi pangan sehari-hari (orang/kg); 4) ketersediaan pangan beras (ada/tidak); 5) sumber pangan beras (bantuan atau sumber lain); dan pendapatan rumah tangga/bulan (Rp).

Untuk mendapatkan gambaran pola konsumsi beras dilakukan analisis deskriptif kualitatif sesuai panduan Sugiyono, (2006), sedangkan untuk mengetahui faktor-faktor yang mempengaruhi konsumsi beras digunakan analisis regresi linier berganda sesuai petunjuk Gujarati \& Porter, (2009) dengan model persamaan $Y=\beta_{0}+\beta_{1} X_{1}+\beta_{2} X_{2}+\beta_{3} X_{3}+\beta_{4} X_{4}+\beta_{5} X_{5}$ dimana:

$\begin{array}{ll}\mathrm{Y} & : \text { konsumsi beras dalam sebulan }(\mathrm{kg}) \\ \beta 0 & : \text { konstanta } \\ \beta_{1}-\beta \mathrm{n} & : \text { koefisien regresi } \\ \mathrm{X}_{1} & : \text { harga beras dalam sebulan }(\mathrm{Rp} / \mathrm{kg} / \mathrm{bulan}) \\ \mathrm{X}_{2} & : \text { pendapatan Konsumen }(\mathrm{Rp} / \mathrm{bulan}) \\ \mathrm{X}_{3} & : \text { jumlah Tanggungan Keluarga }(\mathrm{Orang}) \\ \mathrm{X}_{4} & : \text { tingkat Pendidikan (Tahun) } \\ \mathrm{X}_{5} & : \text { selera } ; 1=\text { beras bulog } ; 2=\text { beras mol }\end{array}$

Analisis data menggunakan bantuan aplikasi SPSS.16 yang dilakukan sesuai petunjuk Santoso, (2008). Kelayakan model akan diuji menggunakan uji $\mathrm{F}$, koefisien determinasi $\left(\mathrm{R}^{2}\right)$, dan uji t. Pengujian untuk pengambilan keputusan dilakukan dengan tingkat kepercayaan 95\% ( $\alpha$ 5\%). Uji F dilakukan untuk mengetahui pengaruh seluruh variabel bebas (X) secara simultan terhadap variabel tetap (Y) dengan kaidah pengambilan keputusan jika nilai signifikans (Sig.) $<0,005(\alpha 5 \%)$ maka $\mathrm{X}$ berpengaruh secara nyata terhadap $\mathrm{Y}$, sebaliknya jika nilai signifikansi (Sig.) $>0,005(\alpha$ 5\%) maka X tidak berpengaruh nyata terhadap Y. Uji t dilakukan untuk mengetahui pengaruh variabel bebas $(\mathrm{X})$ secara parsial terhadap variabel tetap (Y) dengan kaidah pengambilan keputusan jika nilai signifikansi (Sig.) $<0,005(\alpha$ 5\%) maka $X$ berpengaruh secara nyata terhadap Y, sebaliknya jika nilai signifikansi (Sig.) $>0,005(\alpha$ 5\%) maka $\mathrm{X}$ tidak berpengaruh nyata terhadap $\mathrm{Y}$

\section{Hasil dan Pembahasan}

3.1. Identitas Responden

Identitas responden merupakan salah satu indikator yang diperhatikan oleh peneliti dalam mengungkapkan permasalahan yang dihadapi masyarakat $d$ daerah penelitian. Berikut akan diuraikan komponen-komponen dari identitas responden.

a. Umur

Umur merupakan suatu indikator yang menunjukkan kematangan seseorang dalam berpikir. Di samping itu umur mempengaruhi petani dalam mencurahkan tenaganya melaksanakan kegiatan usahatani. Berdasarkan hasil penelitian diperoleh umur responden yang bervariasi, berkisar antara 31-70 tahun. Klasifikasi responden berdasarkan golongan umur dapat dilihat pada Tabel 1.

Tabel 1. Distribusi Responden Berdasarkan Kelompok Umur

\begin{tabular}{cccc}
\hline No & Variasi Umur Responden (tahun) & Jumlah & Persentase \\
\hline 1. & $30-39$ & 80 & $37.78 \%$ \\
2. & $40-49$ & 47 & $20,43 \%$ \\
3. & $50-59$ & 58 & $25,01 \%$ \\
4. & $60-69$ & 43 & $19,56 \%$ \\
\hline Jumlah & & 228 & $100 \%$ \\
\hline
\end{tabular}

Berdasarkan Tabel 1. diketahui bahwa umur petani 30-39 tahun $80 \mathrm{KK}$ atau $37,78 \%, 40-49$ tahun $47 \mathrm{KK}$ atau $20,43 \%, 50-59$ tahun $58 \mathrm{KK}$ atau $25,21 \%$, dan umur 60-69 tahun sebanyak $43 \mathrm{KK}$ atau $19,56 \%$. 
b. Jumlah Tanggungan Keluarga

Jumlah tanggungan keluarga dapat mempengaruhi petani dalam bekerja Semakin banyak anggota keluarga maka semakin banyak tanggungan dan besarnya tanggung jawab yang harus ditanggung oleh kepala keluarga.

Tabel 2. Distribusi Responden Berdasarkan Besarnya Jumlah Tanggungan Keluarga

\begin{tabular}{cccc}
\hline No & Tanggungan Keluarga (orang) & Jumlah (KK) & Persentase (\%) \\
\hline 1. & 2 & 60 & $26,10 \%$ \\
2. & 3 & 43 & $18,70 \%$ \\
3. & 4 & 44 & $19,13 \%$ \\
4. & 5 & 32 & $14,34 \%$ \\
5. & 6 & 21 & $9,13 \%$ \\
6. & 7 & 20 & $8,69 \%$ \\
7. & 8 & 7 & $3,48 \%$ \\
8. & 11 & 1 & $0,43 \%$ \\
\hline Jumlah & & 228 & $100 \%$ \\
\hline
\end{tabular}

Berdasarkan Tabel 2. diketahui bahwa sebagian petani memiliki tanggungan keluarga 2 orang sebanyak $60 \mathrm{KK}$ atau $26,10 \%, 3$ orang sebanyak $43 \mathrm{KK}$ atau $18,70 \%, 4$ orang sebanyak $44 \mathrm{KK}$ atau $19,13 \%$, 5 orang sebanyak $33 \mathrm{KK}$ atau $14,34 \%, 6$ orang sebanyak $21 \mathrm{KK}$ atau 9,13\%, 7 orang sebanyak 20 KK atau 8,69\%, 8 orang sebanyak $7 \mathrm{KK}$ atau 3,48\%, dan 11 orang sebanyak 1 KK atau $0,43 \%$. Keadaan ini menunjukkan jumlah tanggungan keluarga sangat bervariasi.

c. Pendidikan Formal

Pendidikan dapat menjadi salah satu faktor pembentukan pola pikir seseorang agar dapat menyikapi perubahan. Semakin tinggi pendidikan petani maka ia akan selalu berusaha untuk melakukan usahatani secara baik dalam mengonsumsi. Menurut Mosher, (1968), yang menyatakan bahwa tingkat pendidikan akan mempengaruhi petani dalam menjalankan usahataninya. Hasil penelitian, menunjukkan bahwa pendidikan petani pada umumnya masih relatif rendah yang dapat ditunjukkan pada Tabel 3 .

Tabel 3. Distribusi Responden Berdasarkan Tingkat Pendidikan Formal

\begin{tabular}{cccc}
\hline No & Tingkat Pendidikan & Jumlah & Persentase $(\%)$ \\
\hline 1. & SD & 188 & $82,50 \%$ \\
2. & SMP & 21 & $9,18 \%$ \\
3. & SMA & 5 & $2,20 \%$ \\
4. & Sarjana & 14 & $6,12 \%$ \\
\hline Jumlah & & 228 & $100 \%$ \\
\hline
\end{tabular}

Berdasarkan Tabel 3. diketahui bahwa jumlah tingkat pendidikan petani berbeda - beda diantaranya SD sebanyak $188 \mathrm{KK}$ atau 82,50\%, SMP sebanyak $21 \mathrm{KK}$ atau $9,18 \%$, SMA sebanyak $5 \mathrm{KK}$ atau 2,20\%, dan Sarjana sebanyak $14 \mathrm{KK}$ atau $6,12 \%$.

d. Pendapatan

Selisih antara pendapatan kotor usahatani dan pengeluaran total usahatani disebut pendapatan bersih usahatani (Net Farm Income). Pendapatan bersih usahatani mengukur pengambilan imbalan yang diperoleh keluarga petani dari penggunaan faktor-faktor produksi kerja, pengelolaan, dan modal milik sendiri atau pinjaman yang diinvestasikan ke dalam usahatani. Soekartawi, (1986) menyatakan bahwa pendapatan usahatani adalah selisih penerimaan usahatani dengan biaya-biaya yang dikeluarkan. Distribusi pendapatan ditampilkan pada Tabel 4.

Tabel 4. Distribusi Responden Berdasarkan Pendapatan

\begin{tabular}{cccc}
\hline No & Pendapatan (KK) & Jumlah (KK) & Persentase (\%) \\
\hline 1. & Rp. 100.000-500.000 & 215 & $94,35 \%$ \\
2. & Rp. 500.001-1.000.000 & 1 & $0,43 \%$ \\
3 & Rp 1.00.001-2.000.000 & 12 & $5,22 \%$ \\
\hline \multicolumn{2}{l}{ Jumlah } & 228 & $100 \%$ \\
\hline
\end{tabular}

Berdasarkan Tabel 4. diketahui bahwa jumlah pendapatan Rp. 100.000500.000 sebanyak $215 \mathrm{KK}$ atau 94,35\%, dan jumlah pendapatan Rp. 500.001 1000.000 sebanyak $1 \mathrm{KK}$ atau $0,43 \%$, dan pendapatan Rp. 1.000.0012.000.000 sebanyak $12 \mathrm{KK}$ atau $5,22 \%$

\subsection{Pola Konsumsi Beras}

Masyarakat Desa Babotin Maemina mengonsumsi beras dengan rata-rata $24,43 \mathrm{~kg} /$ bulan. Secara detail, konsumsi beras dapat dilihat pada Tabel 5.

Tabel 5. Distribusi Responden Berdasarkan Pola Konsumsi

\begin{tabular}{cccc}
\hline No & Konsumsi (kg/bulan) & Jumlah & Persentase \% \\
\hline 1. & $0-10$ & 45 & $20.43 \%$ \\
2. & $10,01-20$ & 41 & $17.83 \%$ \\
3. & $20,01-30$ & 60 & $26.09 \%$ \\
4. & $30,01-40$ & 46 & $20.00 \%$ \\
5. & $40,01-60$ & 36 & $15.65 \%$ \\
\hline Jumlah & & 228 & $100 \%$ \\
\hline
\end{tabular}

Berdasarkan Tabel 5. konsumsi beras $0-10 \mathrm{~kg}$ sebanyak $45 \mathrm{KK}$ atau $20,43 \%, 10,01-20 \mathrm{~kg}$ sebanyak $41 \mathrm{KK}$ atau 17,83\%, 20,01-30 kg sebanyak 60 KK atau 26,09\%, 30,01-40 kg sebanyak $46 \mathrm{KK}$ atau 20,00\%, dan 40,01-60 kg sebanyak $36 \mathrm{KK}$ atau $15,65 \%$. Dari tabel di atas menunjukkan bahwa konsumsi 20,01-30 lebih banyak dibandingkan dengan yang lainnya.

Rata-rata harga beras di tingkat konsumen sebesar Rp9.951,00 dengan deskripsi harga seperti pada Tabel 6

Tabel 6. Harga Beras di Tingkat Konsumen

\begin{tabular}{cccc}
\hline No & Harga Beras (Rp) & Jumlah & Persentase \% \\
\hline 1. & $4.000-9.000$ & 78 & $34.78 \%$ \\
2. & $9.001-14.000$ & 137 & $59,57 \%$ \\
3. & $>14.000$ & 13 & $5,65 \%$ \\
\hline Jumlah & & 228 & $100 \%$ \\
\hline
\end{tabular}

Berdasarkan Tabel 6. dapat dirincikan bahwa sebanyak $78 \mathrm{KK}$ atau 34,78\% membeli beras dengan harga Rp4.000,00 - Rp,009.000, sebanyak $137 \mathrm{KK}$ atau $59,57 \%$ membeli beras dengan harga Rp9.001,00 - Rp14.000,00 dan sebanyak $13 \mathrm{KK}$ atau 5,65\% membeli beras dengan harga lebih besar dari Rp14.000,00. Hal ini menunjukkan bahwa masyarakat yang mengonsumsi beras dengan harga Rp9.001,00 - Rp14.000,00 lebih banyak.

Menurut Hoang yang dikutip oleh Aminah, (2005) pola konsumsi adalah berbagai informasi yang memberikan gambaran mengenai jumlah dan jenis bahan makanan yang dimakan setiap hari oleh satu orang dan mempunyai ciri khas untuk suatu kelompok masyarakat tertentu. Pola makan adalah cara seseorang atau sekelompok orang (keluarga) dalam memilih makanan sebagai tanggapan terhadap pengaruh fisiologi, psikologis, kebudayaan dan sosial.

Pola konsumsi masyarakat Desa Babotin Maemina pada tahun-tahun sebelumnya hanya mengonsumsi jagung, pisang, dan ubi. Namun pada tahun 2012 masyarakat Desa Babotin Maemina mulai beralih pola konsumsi dari pangan non beras ke beras karena pengetahuan masyarakat mengenai beras yang mengandung karbohidrat lebih besar dari pada pangan non beras. Hal ini yang membuat masyarakat mulai beralih mengonsumsi beras.

Meskipun pola konsumsi dari pangan non beras ke beras telah diterapkan namun tidak begitu lama masyarakat tetap beralih ke pangan non beras seperti jagung dan ubi karena beralasan masyarakat cepat bosan dan ada yang mengisukan bahwa mengonsumsi beras terus menerus dapat menimbulkan penyakit. Hal inilah yang membuat masyarakat Desa Babotin Maemina mulai mengatur pola konsumsi yaitu pagi dan malam masyarakat mengonsumsi beras sedangkan pada siang hari masyarakat mengonsumsi jagung dan ubi.

\subsection{Faktor-Faktor yang Mempengaruhi Konsumsi Beras}

Koefisien determinasi $\left(\mathrm{R}^{2}\right)$ menunjukkan bahwa sebesar $89,3 \%$ konsumsi beras dijelaskan oleh variabel harga beras, pendapatan konsumen, jumlah tanggungan, tingkat pendidikan dan selera konsumen sedangkan 10,7\% persen dapat dijelaskan di luar model. Data Tabel 7. menunjukkan bahwa secara simultan variabel harga beras, pendapatan konsumen, jumlah tanggungan, tingkat pendidikan dan selera konsumen berpengaruh secara nyata terhadap konsumsi beras.

Tabel 7. Anova Regresi Linear Berganda

\begin{tabular}{lccccc}
\hline \multicolumn{1}{c}{ Model } & Sum of Squares & df & Mean Square & F hitung & Sig. \\
\hline Regression & 53.272 & 5 & 10.654 & 371.043 & $.000^{\mathrm{a}}$ \\
Residual & 6.375 & 222 & .029 & & \\
\hline Total & 59.647 & 227 & & & \\
\hline
\end{tabular}

Berdasarkan data pada Tabel 8. Diperoleh persamaan regresi $\mathrm{Y}=7,045-$ $0,512 X_{1}-0,029 X_{2}+0,794 X_{3}+0,028 X_{4}+0,001 X_{5}$.

Tabel 8. Koefisien Regresi

\begin{tabular}{cccccc}
\hline \multirow{2}{*}{ Model } & \multicolumn{2}{c}{ Unstanardized Coefficients } & $\begin{array}{c}\text { Standardized } \\
\text { Coefficients }\end{array}$ & \multirow{2}{*}{$\mathrm{t}$} & Sig. \\
\cline { 2 - 4 } & $\mathrm{B}$ & Std. Error & Beta & & \\
\hline (Constant) & 7.045 & .609 & & 11.566 & .000 \\
$\mathrm{X}_{1}$ & -.512 & .054 & -.318 & -9.409 & .000 \\
$\mathrm{X}_{2}$ & -.029 & .023 & -.036 & -1.276 & .203 \\
$\mathrm{X}_{3}$ & .794 & .040 & .698 & 19.822 & .000 \\
$\mathrm{X}_{4}$ & .028 & .050 & .015 & .559 & .577 \\
$\mathrm{X}_{5}$ & .001 & .040 & .001 & .025 & .980 \\
\hline
\end{tabular}

Masing-masing variabel bebas memiliki pengaruh yang berbeda terhadap konsumsi beras yang dapat diuraikan sebagai berikut: a. Harga Beras

Pada variabel harga nilai signifikansi sebesar $0,000<0,05(\alpha 5 \%)$ dapat menunjukkan bahwa harga berpengaruh terhadap konsumsi beras. Hal ini dapa disimpulkan bahwa semakin tinggi harga suatu beras maka konsumen di Desa Babotin Maemina akan menurunkan konsumsi beras. Jika harga beras meningkat satu rupiah maka permintaan akan beras akan menurun sebesar $0,512 \mathrm{~kg}$. Hal ini sesuai dengan penelitian Hasyim, (2007) yang melaporkan 
bahwa harga beras berpengaruh nyata secara statistik terhadap konsumsi beras di Sumatera Utara.

b. Pendapatan

Pada variabel pendapatan nilai signifikansi $0,203>0,05 \quad\left(\begin{array}{lll}\alpha & 5 \%\end{array}\right)$ menunjukkan bahwa pendapatan tidak berpengaruh nyata terhadap konsumsi beras. Meskipun pendapatan konsumen meningkat namun tidak berpengaruh terhadap pembelian beras. Hal ini sesuai dengan penelitian Sunani, (2009) yang melaporkan bahwa pendapatan seseorang tidak berpengaruh nyata terhadap konsumsi beras di Kabupaten Siak, Riau.

c. Jumlah Tanggungan

Pada variabel jumlah tanggungan nilai Signifikansi $0,000<0,05(\alpha 5 \%)$ menunjukkan bahwa jumlah tanggungan berpengaruh terhadap konsumsi beras. Rata-rata konsumsi perkapita beras dari 228 responden adalah 6 $\mathrm{kg} / \mathrm{kapita} / \mathrm{bulan}$. Setiap penambahan satu orang sebagai tanggungan keluarga maka konsumsi beras akan meningkat $0,749 \mathrm{~kg}$. Hal ini sesuai dengan penelitian Shavana $d k k$., (2014) yang melaporkan bahwa jumlah tanggungan berpengaruh terhadap jumlah barang yang diminta di kota Medan.

d. Tingkat Pendidikan

Nilai signifikansi untuk variabel tingkat pendidikan sebesar 0,577 dan lebih besar dari $0,05(\alpha .5 \%)$ yang berarti tingkat pendidikan tidak berpengaruh nyata terhadap konsumsi beras. Konsumsi beras merupakan kebutuhan pokok yang secara jelas tidak tergantung pada tingkat pendidikan seseorang. Hal ini sejalan dengan penelitian Bangun $d k k$., (2013) yang juga melaporkan bahwa tingkat pendidikan tidak berpengaruh terhadap jumlah beras yang diminta di Desa Dua Ramunia, Kecamatan Beringin, Kabupaten Deli Serdang.

e. Selera

Nilai signifikansi untuk variabel selera sebesar 0,980 dan lebih besar dari $0,05(\alpha 5 \%)$ yang berarti selera tidak berpengaruh nyata terhadap konsumsi beras. Konsumsi beras merupakan kebutuhan pokok dan masyarakat desa Babotin Maemina tidak melihat seberapa kualitas, merek dan jenis beras yang dikonsumsi. Dari 228 responden maka mereka hanya mengonsumsi beras mol dan beras Dolog. Keterbatasan pilihan yang tersedia menyebabkan masyarakat akan mengonsumsi beras apa saja yang tersedia. Hal ini sesuai dengan penelitian Hermawan, (2014) yang menunjukkan bahwa selera tidak memiliki pengaruh terhadap perilaku konsumen.Identitas responden merupakan salah satu indikator yang diperhatikan oleh peneliti dalam mengungkapkan permasalahan yang dihadapi masyarakat di daerah penelitian. Berikut akan diuraikan komponen-komponen dari identitas responden.

\section{Simpulan}

Tahun 2012 masyarakat Desa Babotin Maemina mulai beralih dari pola konsumsi pangan non beras ke beras. Rata-rata konsumsi beras dari $228 \mathrm{KK}$ di Desa Babotin Maemina adalah 24,43 kg/kapita/bulan dengan rata-rata harga beras di tingkat konsumen Rp9.951,00. Harga beras dan jumlah tanggungan keluarga secara nyata berpengaruh terhadap konsumsi beras sedangkan pendapatan konsumen, tingkat pendidikan dan selera tidak berpengaruh terhadap konsumsi beras. Jika harga beras meningkat satu rupiah maka permintaan akan beras akan menurun sebesar $0,512 \mathrm{~kg}$ dan setiap penambahan satu orang sebagai tanggungan keluarga maka konsumsi beras akan meningkat $0,749 \mathrm{~kg}$.

\section{Pustaka}

Aminah, S. 2005. Gambaran Konsumsi Makanan Dan Status Gizi Balita 0-24 bulan di Kelurahan Tanjung Leidong Kecamatan Kualuh Leidong Kabupaten Labuhan Batu Propinsi Sumatera Utara Tahun 2005. Skripsi. Medan: Universitas Sumatera Utara.

Bangun, H.P.P., Hutajulu, S. \& Tiurland, A. 2013. Analisis Pola Konsumsi Pangan dan Tingkat Konsumsi Beras di Desa Sentra Produksi Padi (Studi Kasus: Desa Dua Ramunia, Kecamatan Beringin, Kabupaten Deli Serdang). Journal of Agriculture and Agribusiness Socioeconomics, 2(7): $1-7$.

BPS Kab. Malaka 2016. Kabupaten Malaka dalam Angka 2016. Betun: Badan Pusat Statistik Kabupaten Malaka.

BPS Provinsi NTT 2016. Nusa Tenggara Timur dalam Angka 2016. Kupang: Badan Pusat Statistik Provinsi NTT.

Gujarati, D.N. \& Porter, D.C. 2009. Basic Econometrics. McGraw-Hill Irwin.

Hasyim, H. 2007. Analisis Faktor Faktor yang Mempengaruhi Ketersediaan Beras di Sumatera Utara. Tesis. Medan: Universitas Sumatera Utara.

Hermawan, B.A. 2014. Analisis pengaruh faktor harga, selera, prestise, dan kualitas terhadap perilaku konsumen dalam membeli sebuah produk: studi kasus pada mahasiswa Fakultas Ekonomi pengguna produk helm INK di Universitas Sanata Dharma Yogyakarta. [Skripsi] Yogyakarta: Sanata Dharma University.

Mosher, A.T. 1968. Menggerakkan Dan Membangun Pertanian: Sjarat Mutlak Pembangunan Dan Modernisasi. Jakarta: C.V. Yasaguna.

Muttaqin, A.Z. 2008. Analisis Konsumsi Beras Rumah Tangga dan Kecukupan Beras Nasional Tahun 2002-2007. Tesis. Bogor: Institut Pertanian Bogor.

Santoso, S. 2008. Panduan Lengkap Menguasai Spss 16. Jakarta: Elex Media Komputindo.

Shavana, B.D., Darus, H. \& Lubis, S.N. 2014. Faktor-faktor yang Mempengaruhi Permintaan dan Penawaran Minyak Goreng Curah di Kota Medan. Journal of Agriculture and Agribusiness Socioeconomics, 3(3): 115 .
Soekartawi 1986. Ilmu Usahatani dan Penelitian untuk Pengembangan Petani Kecil. Jakarta: Universitas Indonesia Press.

Sugiyono, 2006. Metode Penelitian Kuantitatif, Kualitatif dan $R \& D$. Bandung: Alfabeta.

Sunani, N. 2009. Analisis faktor-faktor yang mempengaruhi produksi dan konsumsi beras di Kabupaten Siak, Riau. Skripsi. Bogor: Institut Pertanian Bogor. 